Pedagogía y Saberes $n .^{\circ} 52$

Universidad Pedagógica Nacional

Facultad de Educación. 2020. pp. 9-22

\title{
Pedagogía e historia. La educación como tiempo de la historia*
}

\section{Artículo de investigación}

Pedagogy and History. Education as Time of the History

Pedagogia e história. A educação como tempo da história

María Isabel Heredia Duarte**

\section{Para citar este artículo:}

Heredia, M. (2020). Pedagogía e historia. La educación como tiempo de la historia. Pedagogía y Saberes, 52, 9-22. DOI: https:// doi.org/10.17227/pys.num52-10628

* Este artículo es producto de las investigaciones adelantadas en el proyecto de tesis en el doctorado en Educación en la Universidad Pedagógica Nacional.

** Profesora de la Facultad de Educación de la Universidad Pedagógica Nacional. Estudiante del Doctorado en Educación Interinstitucional en la misma universidad e investigadora del Grupo de Historia de la Práctica Pedagógica, GHPP.

Correo electrónico: miherediad@pedagogica.edu.co Código ORCID: http://orcid.org/0000-0002-9107-2493 


\title{
Resumen
}

Desde una perspectiva histórico-filosófica, este artículo de investigación propone una relación cercana entre pedagogía e historia. Como producto de las investigaciones de la autora en el marco de su tesis de doctorado, el trabajo realiza un recorrido por la historia del futuro, correlacionándolo con la educación, para demostrar que, si bien lo que llamamos tiempo es la relación entre el pasado y el futuro, es la educación como posibilidad de perfeccionamiento humano lo que la hace posible. En este sentido, la educación es el futuro mismo. Por tanto, la educación sería organizadora del tiempo histórico y no un correlato menor en el desarrollo de la modernidad. Esta postura permite interrogar algunas verdades que hasta el momento han sido incuestionables. Una de ellas es la relación intrínseca entre pedagogía y sociología, que ha fortalecido la creencia de que la educación es, por excelencia, un hecho social. Este piso sociológico habría encerrado la educación en una práctica, lo que ha provocado, en parte, su recorte como proyecto humano, más allá de la sociedad. Finalmente, se vislumbra una crisis de la historia como crisis de la educación, basada en el encierro en el presente y en la imposibilidad de formular fines genuinamente generales.

\section{Palabras clave}

historia de la educación; filosofía de la educación; práctica pedagógica; crisis de la educación

\begin{abstract}
From a historical-philosophical perspective, this article proposes a close nexus between pedagogy and history. Based on the author's PhD research, this work runs through the history of the future, correlating it with education, to demonstrate that, although what we call time is the link between past and future, is education as a possibility of human improvement what makes it possible. In this sense, education is the very future. Therefore, education would be an historical time organizer and not a minor correlate in modernity development. This position allows us to interrogate some truths that until now have been unquestionable. One of them is the intrinsic association between pedagogy and sociology, which has strengthened the belief that education is, par excellence, a "social fact". This sociological background has confined education in a "practice", which has caused, in part, its curtailment as a human project, besides society. Finally, there is a crisis in history as a crisis in education, because of the confinement in the present and the impossibility in formulating genuinely general purposes.
\end{abstract}

\section{Keywords}

history of education; philosophy of education; pedagogical practice; crisis of education

\section{Resumo}

Desde uma perspectiva histórico-filosófica, esse artigo propõe una estreita relação entre pedagogia e história. Com base nos resultados das pesquisas desenvolvidas pela autora no marco da sua tese de doutorado, o trabalho faz um recorrido pela história do futuro, correlacionando-o com a educação, para demonstrar que, ainda que o que chamamos de tempo é a relação entre o passado e o futuro, a educação é, como possibilidade do aperfeiçoamento humano, o que a faz possível. Nesse sentido, a educação é o futuro mesmo. Portanto, a educação seria um organizador do tempo histórico e não um correlato menor no desenvolvimento da modernidade. Esta postura permite questionar algumas verdades inquestionáveis até agora. Uma delas é a relação intrínseca entre pedagogia e sociologia, que tem fortalecido a crença na educação como um "fato social" por excelência. Este fundamento sociológico tem causado, em parte, seu recorte como projeto humano, além da sociedade. Finalmente, se percebe de relance uma crise da história como crise da educação, baseada no confinamento no presente e na impossibilidade de formular propósitos genuinamente gerais.

\section{Palavras-chave}

história da educação; filosofia da educação; prática pedagógica; crise da educação 


\section{Introducción}

$\mathrm{P}$ ensar la pedagogía más cercana a la historia y un poco más lejana a la sociología puede ser materia del trabajo que aquí se presenta. En su revisión, el lector encontrará algunas sorpresas que también lo fueron para la autora. Pensar que la educación es tiempo, que si la pensamos como una práctica social podemos ir en detrimento de ese tiempo y que, como la educación es tiempo, puede también detenerse y dilatarse hasta llegar a un posible fin de la historia, no son asuntos que se digieran con facilidad.

Estas ideas se han desarrollado a partir de las investigaciones realizadas desde la tesis en el Doctorado en Educación que adelanto en la Universidad Pedagógica Nacional. Planteo aquí la hipótesis general que acompaña el trabajo, y se basa en el hecho de que la educación, como asunto propio de la modernidad, se constituye a partir de un rasgo que poco hemos avistado. Este rasgo distintivo es su condición de futuro abierto que, a su vez, hace posible el tiempo histórico.

Las ideas con las que abrí esta introducción, que reconozco pueden parecer peregrinas o inconexas, serán explicadas en los cuatro apartados que componen el artículo. Como se trata de una investigación en ciernes, no he encontrado una forma distinta de exponerlas, por esto, no me queda más remedio que solicitar al lector paciencia.

En el primer apartado, titulado "Pedagogía e historia, más que una relación cercana", se exponen las intrincadas relaciones entre pedagogía e historia, mediadas por la relación yuxtapuesta entre los objetos centrales de las dos disciplinas, es decir, la educación y el tiempo. Aquí se dibuja un pequeño mapa de la historia del futuro, y de la forma en que, después del siglo XVI, este futuro se proyecta como un asunto secular, liberado de las percepciones religiosas y míticas, para terminar representándose como un futuro abierto. Esta posibilidad de apertura que adquiere el tiempo futuro es dada por la posibilidad de diseño que es en sí lo que hace posible interpretarlo como educación.

En el segundo apartado, "La sociedad como phusis contemporánea de la pedagogía”, se exponen algunos argumentos que procuran mostrar que la educación, por lo menos para el siglo $\mathrm{xx}$, ha sido definida primordialmente desde un principio sociológico, antes que histórico o antropológico. La expansión del enunciado "la educación es un hecho social" ha sido la base para pensar, imaginar e intentar definir la educación. Esta postura va a tener implicaciones importantes para la transformación de la noción de educación, pues al reducirla a una práctica social, se limita a la vez su condición de futuro abierto, provocando el recorte de sus fines.

En "La naturaleza teleológica de la educación" se dibuja un mapa del significado de los fines de la historia como fines de la educación, por cuanto se trata de proyectos de perfeccionamiento humano. Para esto me baso en algunas obras de Immanuel Kant, y su posibilidad de lectura desde la pedagogía. Este apartado retoma los planteamientos de la primera parte, y establecen por qué la educación, además de una práctica, también posee una naturaleza teleológica que no se debe perder de vista, pues se corre el riesgo de caer en un posible presentismo.

Para terminar, el apartado "La crisis de la educación como crisis del tiempo" plantea como conclusión el problema contemporáneo de la vuelta sobre la finitud del futuro. Esta demarcará un problema en la pérdida de la educación como posibilidad de perfectibilidad humana, lo que se traduce en una gran crisis del presente como crisis de la historia. Si el futuro, que es la educación misma, se limita a la solución de problemas contingentes del presente, tal vez estemos frente a un problema de detención del tiempo y en una crisis general de la historia.

\section{Pedagogía e historia, más que una relación cercana}

Ante la pregunta ¿qué pueden tener en común la pedagogía y la historia?, no valen respuestas referentes a la historiografía de la pedagogía o al hecho de hacer historia de sus objetos. Más bien, este interrogante orienta hacia la búsqueda de un puente real de intercambio entre las dos disciplinas. Sostendré en estas líneas que el puente está trazado por la relación estrecha entre educación y tiempo. Pero, para probar esta hipótesis, es necesario demostrar que tiempo y educación tienen imbricaciones tan profundas que puede resultar difícil su distinción; esto será abordado a lo largo del artículo.

Marc Bloch (1982) definió de manera magistral la historia cuando escribió que era "la ciencia de los hombres en el tiempo" (p. 26). Así la historia no se encargaría solo de lo humano, sino que a lo humano habría que ubicarlo en la atmósfera que llamó duración. Pero el tiempo de la historia no es el mismo tiempo que puede ser asimilado en otras disciplinas, este no pasa o sucede y tampoco se mide o se fabrica, sino que al ser presentado como "el plasma en el que se bañan los fenómenos y algo así como el lugar de 
su inteligibilidad" (p. 26), expone que los fenómenos referentes al hombre y el hombre mismo no pueden comprenderse por fuera del tiempo.

Decir que la preocupación de la historia es temporal antes que antropológica puede resultar algo extraño, y esta extrañeza se debería al hecho de que el tiempo tiende a pasar desapercibido, o en otro caso, a ser percibido como exterior al sujeto y por tanto naturalizado. Kant (2007a) tal vez tuvo la respuesta, al establecer su condición a priori:

\section{El tiempo no es algo que subsista por sí mismo, o que sea inherente a las cosas, como determinación objetiva, y que por tanto permanezca si se hace abstracción de todas las condiciones subjetivas de la intuición de ellas, pues en el primer caso, aun sin objeto efectivamente real, sería algo que sería efectivamente real. (p. 101)}

Por tanto, como condición subjetiva y trascendental, ningún fenómeno (relativo a objetos de la intuición sensible) estaría por fuera del tiempo, lo que hace difícil pensarlo como extraño.

Pero, además del hecho de que sea uno de los principios del conocimiento a priori, también constituye, al parecer, el propio motor y significado de la historia. Jean-Pierre Le Goff (1991) estableció — al analizar algunas escatologías antes de la modernidad- la recurrencia a identificar en la memoria (el pasado) la felicidad y el bienestar humanos. Llamó a este fenómeno edades míticas, compuestas por edades de oro, el país de Cucaña o el Milenio, y que tenían la función de hacer llevadera la vida de los hombres estando las esperanzas puestas en su retorno. Siguiendo los análisis del historiador francés, estas edades míticas "han sido uno de los primeros esfuerzos - un esfuerzo plurisecular - para pensar y domesticar la historia" (p. 44), pero también es patente que en este esfuerzo el futuro no se expone como un tiempo abierto a la novedad, sino que es en sí el retorno del pasado.

Para ser estrictos, no podemos calificar las escatologías de las edades míticas de Le Goff como progreso para el tiempo moderno. Sin duda, para el historiador de la Escuela de los Annales, el progreso forma parte de la renovación de las edades míticas y su relación con el sentido de la historia:

Cuando se percibe la edad de oro de las sectas, la edad de oro de los hippies y de los ecologistas, la edad de oro de los economistas del crecimiento cero, se puede pensar en que las edades míticas no están muertas y que conocerán una renovatio de la mentalidad, quizás, al menos en las teorías de los historiadores. (p. 45)
En cierto sentido, es significativo el hecho de que la historia reciba la responsabilidad del buen destino de los pueblos. Sin embargo, también debe tenerse presente que la escatología no había pertenecido del todo al registro de la historia. Las edades míticas de Le Goff están ubicadas de manera primordial en la literatura, la oralidad, la mitología e incluso en la filosofía. Fue solo hasta el siglo XVIII el momento en que se ve claramente una relación concreta con la historia, cuando empiezan a experimentarse otras formas del tiempo.

Reinhart Koselleck (1993), al indagar sobre el tiempo histórico, examinó la forma en que "se elaboran experiencias del pasado en una situación concreta y cómo expectativas, esperanzas o pronósticos se discuten en el futuro" (p. 16). Este historiador sostiene que, al transcurrir las generaciones históricas, las relaciones entre pasado y futuro se modifican, y a medida que los hombres experimentan el constante tiempo nuevo de la modernidad, "el reto del futuro se ha hecho cada vez mayor" (p. 16); que esto afecte a sus contemporáneos, no es causa del mundo sobredimensionado técnica e industrialmente, o de las velocidades de los cambios que se han atribuido al desarrollo de la técnica, sino al hecho de "experimentar la historia como tiempo nuevo". Este suceso ocurriría a partir del siglo XVIII, momento de modernización del concepto de historia: "nuestro moderno concepto de historia es un resultado de la reflexión ilustrada sobre la creciente complejidad de la 'historia en general', reflexión en la que las condiciones de la experiencia se sustraen progresivamente a esa misma experiencia" (p. 17). Surgen entonces conceptos complementarios a esa historia general, como "revolución, azar, destino, progreso o desarrollo", a los que Koselleck somete a análisis semántico, no con una finalidad histórico-lingüística, según afirma, sino con la intención de "buscar su constitución lingüística de experiencias del tiempo allí donde aparecieron en la realidad pasada" (p. 17).

Kant utilizó el término quiliasmo - separándolo del milenarismo y acercándolo a la filosofía de la historia-para exponer la idea de perfeccionamiento como el plan oculto de la naturaleza, entendido "como el único estado en el que puede desarrollar plenamente todas sus disposiciones en la humanidad" (p. 57). Quiliasmo que "no es quimérico ni mucho menos", pues todo dependería de descubrir, en la contingencia de las acciones de los hombres (es decir, en la historia), "el curso semejante de la intención de la Naturaleza" (p. 58). La propuesta de la razón de ser de la historia consistiría en conocer los cursos, 
para luego trazar la órbita y conocer, de manera conjeturada pero bastante certera, el quiliasmo de la naturaleza (Kant, 1984, p. 58).

Las reflexiones de Kant nos llevan a pensar que el trabajo de la historia estaría dado, en esencia, en función del futuro. Se trataría, según el filósofo alemán, de encontrar un hilo conductor que no solo debería servir para explicar el juego enmarañado de cosas humanas o realizar con ella cálculos políticos, sino para

[...] marcar una perspectiva consoladora del futuro en la que se nos represente la especie humana en la lejanía cómo va llegando, por fin, a ese estado en que todos los gérmenes depositados en ella por la Naturaleza se pueden desarrollar por completo y puede cumplir con su destino en este mundo. (p. 63)

Este futuro, entonces, se inscribe también en cierta intención racional en el teatro de la historia del género humano, y este sentido, constituye una lógica del plan natural, como triunfo absoluto de las promesas de la modernidad (Kant, 1984).

En definitiva, lo que se intenta hacer notar es que el futuro no es una realidad existente desde siempre y que hay unas condiciones históricas que lo instituyen como promesa, y en este sentido, movilizan la racionalidad humana y sus diversas formas de expresión o concreción. Es la existencia del futuro como un horizonte abierto el que posibilita el movimiento (y por tanto el cambio) como condición del tiempo. En otras palabras, el tiempo es tiempo porque, en efecto, se mueve: "aquí añado que el concepto del cambio y con él el concepto del movimiento (como cambio de lugar) no son posibles sino mediante y en la representación del tiempo" (Kant, 2007a, p. 43). Ahora bien, este movimiento no es posible de ser reconocido sin el desarrollo de la racionalidad moderna que reorganizó la idea de futuro. Es decir, si podemos observar que las sociedades se han transformado en la historia, es porque en definitiva estamos en el orden del tiempo (en su relación con el pasado y el futuro), o dicho a la manera de Foucault (2005), en un orden del discurso del tiempo.

Así historia, instituida como disciplina en la modernidad, es de cierta manera un orden del tiempo. Como Koselleck bien lo ha mostrado, las sociedades premodernas no estaban diseñadas para vivir en constante transformación, como ocurre con los tiempos modernos contemporáneos. Las propias investigaciones de Le Goff nos permiten conjeturarlo, pues, como lo vimos, el futuro no consistía en una marcha hacia adelante, sino en caminar hacia atrás, regresando al origen. Veamos como ejemplo lo que destaca de la escatología guaraní:
Los guaraníes creen que una catástrofe natural, incendio o diluvio, habría destruido a un mundo anterior y están convencidos de que se repetirá. La única posibilidad de huir de este cataclismo último es refugiarse a tiempo en la "Tierra sin Mal" o "Cielo", fuera del tiempo y de la historia, sin dolor, ni enfermedades, ni injusticias. Estas migraciones se apoyan sobre la idea de que el mundo conoce una extinción, un estancamiento cósmico tal que él mismo aspira a su propio fin, e invoca al Creador que podrá llevar a cabo luego una nueva creación. (Le Goff, 1991, p. 56)

Lo que distingue estas escatologías de la teleología moderna es la existencia del futuro como posibilidad abierta. De manera que el futuro no sería más un retorno al origen o una cualidad finita que se agotaba en las predicciones del fin del mundo, o aquel tiempo natural medido por los fenómenos de la naturaleza como las estaciones, el día y la noche. El tiempo de la modernidad se organizó a partir de la filosofía del progreso y para esto fue necesaria su representación en una línea que avanzaba hacia el horizonte, como metáfora del paisaje de experiencias posibles que se renueva de manera continua. Pasar de un tiempo natural y religioso a un futuro abierto no fue de hecho una tarea sencilla. Según las apreciaciones de Koselleck (1993), el fenómeno de la Reforma religiosa fue central en la reinterpretación del futuro, pues, al parecer, produjo cierto proceso de secularización, necesario para la "formación de la experiencia moderna del tiempo" (p. 28). En este sentido, la Iglesia ya no sería la única portadora del futuro: "ni la Iglesia ni los poderes mundanos eran capaces de sujetar las energías que irrumpieron en el mundo de Europa con Lutero, Zuinglio y Calvino" (p. 26). La experiencia de las guerras religiosas y su neutralización política instauraron la posibilidad de un futuro nuevo, distinto al religioso y mítico, en sentido estricto, un futuro de orden político.

Una vez liberado del encierro en la finitud por el apocalipsis bíblico y las prácticas de predicción astrológicas, el futuro resurgiría en dos versiones interconectadas, una como pronóstico racional y otra como la teoría de la historia (Koselleck, 1993). Estas dos versiones, sin embargo, mantenían para el siglo XVII cierta naturaleza esperanzadora sobre la salvación humana. No obstante, el pronóstico racional, utilizado en especial por los monarcas absolutos en el ejercicio de la diplomacia, el futuro aún seguía siendo finito:

El pronóstico racional se limita a posibilidades intramundanas, pero precisamente por eso produce un excedente de dominio estilizado del mundo. El tiempo se refleja siempre en el pronóstico de 
una forma inesperada; lo que era siempre igual en la esperanza escatológica queda disuelto por la novedad continua de un tiempo que se escapa en sí mismo y que es atrapado por el pronóstico. Así considerado desde la estructura temporal, se puede comprender el pronóstico como el factor de integración del Estado, que traspasa el mundo que se le ha entregado a un futuro limitado. (p. 33)

De alguna manera, el pronóstico racional en el marco del gobierno, el estudio de la población y el uso de las estadísticas le dieron un impuso secular al futuro. Sin embargo, a la manera como Koselleck lo presenta, fue la filosofía de la historia la que hizo posible el progreso expuesto como línea continua hacia el perfeccionamiento humano:

\begin{abstract}
Quien liberó el comienzo de la modernidad de su propio pasado y también abrió con un nuevo futuro nuestra modernidad fue, sobre todo, la filosofía de la historia. Desde las sombras de la política absolutista se formó, primero ocultamente y luego de forma abierta una ciencia del tiempo y del futuro que surgió de una arriesgada combinación entre política y profecía. Se trata de una mezcla, propia del siglo XVIII, entre pronóstico racional de futuro y esperanza cierta de la salvación, que forma parte de la filosofía del progreso. (p. 36)
\end{abstract}

El nacimiento de la historia, podríamos decir, estaría determinado por la reorganización del tiempo futuro como posibilidad del progreso. A partir de aquí historia y educación recorren caminos imbricados y se matizan sus propósitos. ${ }^{1}$ La pedagogía, según las investigaciones de Carlos Noguera (2012), tampoco fue ajena a toda esta transformación por la que ha transitado la historia. Así como Koselleck identificó un proceso de secularización y estatización del futuro después de la Reforma - que daría paso a un control estatal del futuro desde el siglo Xvi hasta el siglo XVIII - Noguera, al analizar el proceso de pedagogización (disciplinarización) de la sociedad europea, llegó a conclusiones relativamente equiparables. Basado en los aportes de Michel Foucault (1990) sobre el poder disciplinar y las artes de gobierno de Senellart, establece que fue precisamente después de

1 Es probable que quien lea estas líneas le parezca extraño que equipare historia con educación. Para ser más precisos, esta equiparación no es con la historia que conocemos, sino con un nivel más amplio, aquella que reflexiona sobre su naturaleza y que normalmente se distingue como filosofía de la historia. Algo similar podemos decir de la educación, que al reflexionar sobre sus fines, no nos estaríamos refiriendo al sistema educativo o a la idea extendida de que se trata de un hecho social, sino de su dimensión filosófica. De manera que voy a continuar utilizando las nociones de historia y educación sin acudir al adjetivo filosófico, aunque con estas aclaraciones. la Reforma el momento en que se extiende el proceso de pedagogización de la sociedad. Esta pedagogización consistiría en un nuevo umbral tecnológico del poder disciplinar (p. 77), que, al igual que como lo vimos en el futuro, se produce a partir del encuentro entre la tradición del cristianismo y el gobierno secular del Estado:

En el paso del umbral tecnológico del poder disciplinar es posible el encuentro y la articulación de dos procesos: la expansión del pastorado cristiano entre los siglos XVI y XVII, y la aparición de la razón del Estado en el siglo XVII. Un proceso de orden religioso y otro de orden político. A través de las técnicas disciplinarias (aisladas en las instituciones monásticas durante la Edad Media), el poder pastoral - regimen - consiguió durante el siglo XVIII, expandirse en la población bajo la forma de adoctrinamiento, la escolarización y la moralización; a partir del siglo XVII, y también gracias a las técnicas disciplinarias constitutivas de la policía, el poder político - regnum - dio forma a la res publica. (p. 78)

Implica, bajo este análisis, que el problema de gobernamiento se constituye por esos tiempos en un asunto político que desplaza a la res pastoralis (Noguera, 2012). Podemos llevar a cabo estos mismos análisis a lo expuesto por Koselleck, pues en efecto se demuestra una "procedencia religiosa del gobierno" del futuro a una razón del futuro desde el Estado. Tanto en las exploraciones de Koselleck como las de Noguera, la práctica secular del gobierno y la aparición de la población son centrales. Lo son en el caso de los procesos de pedagogización y en la aparición del futuro como manifestación del tiempo en movimiento, cuestiones sin las que no sería posible, unos cuantos años después, la conformación de la historia y la pedagogía como disciplinas.

Tanto la historia como la pedagogía tienen una relación profunda con el desarrollo del humanismo y la filosofía del progreso. Sin embargo, el puente que tienden no se basa de manera exclusiva en estos dos aspectos que, a la larga, son también fundamentos constitutivos de cualquier ciencia moderna. El puente entre la historia y la pedagogía lo viene a trazar en realidad el hecho de que la educación puede comprenderse como el tiempo de la historia.

La educación, más que un concepto o una práctica, es posible tratarla como una gran estructura sobre la que se edificó el humanismo moderno. El humanismo fue posible gracias a la organización de la filosofía de la historia, para la que implicó la aparición del futuro como un asunto abierto. El nacimiento del futuro bajo esta rúbrica tuvo varias implicancias, entre otras, 
una experimentación distinta del tiempo. Casi que podríamos decir que, en lo que respecta a la modernidad a partir del siglo XVIII, el tiempo por fin se mueve, no sobre sí mismo como un espiral, hacia atrás persiguiendo una edad de oro, hacia un final apocalíptico inevitable o al compás de la naturaleza; sino hacia un horizonte único de perfección humana. Esta sería la razón temporal de la educación, que como proyecto humano, no sería otra cosa que el futuro. El futuro es la educación, la razón humana de perfección, y a la vez el motor de la historia. Pero para comprender la educación como tiempo de la historia es preciso revisar, además de su naturaleza teleológica, la honda problemática sobre su concepto. Asuntos que se abordarán en los apartados siguientes.

\section{La sociedad como phusis contemporánea de la pedagogía}

En la Ley General de Educación, los académicos, el Ministerio de Educación Nacional e incluso en el lenguaje común de los maestros y políticos la noción de práctica asociada a la educación o la pedagogía es recurrente. Aunque pueda manifestarse desde distintas posturas y matices, o, aunque se haya convertido en una imagen que determina tanto lo que hace un maestro en aula como incluso aquello que puede referir a la pedagogía como ciencia práctica, lo cierto es que, en estos momentos, hablar de práctica (presentada algunas veces como pedagógica, otras como educativa) se considera la forma correcta de referirse a la pedagogía.

El énfasis puesto en la educación como un asunto práctico parece no tener contradictores. Sin embargo, es probable que tal postura haya desplazado la posibilidad de pensar la educación también como un asunto de orden metafísico, y en este mismo sentido, metahistórico. También es probable que la tendencia a interpretar la educación como una práctica o un hecho social se haya impulsado a partir de la amplia difusión de la obra de Emile Durkheim durante el siglo XX, por lo menos así lo ha sido en Colombia. ${ }^{2} \mathrm{El}$

2 Esto forma parte de unos hallazgos parciales realizados en una investigación en la que he venido participando con el Centro de Investigaciones de la Universidad Pedagógica Nacional (CIUP). La exploración del concepto de pedagogía en las tesis de grado de la universidad durante la década de 1980 dejan en claro que la pedagogía se ha entendido y enseñado básicamente desde dos posturas: una tendencia empiricista que refiere a al hecho de asumir la pedagogía como una práctica o una herramienta, y la otra, el predominio de la sociologización, que establece tanto que el fin de la pedagogía sea fortalecer los procesos de socialización, como la pedagogía definida desde y para la sociedad. problema radica en que esta concepción práctica de la educación se ha extendido a campos más allá de las ciencias de la educación y la pedagogía, llegando incluso a imponerse sobre las políticas educativas, pues recordemos que tanto en la Constitución Nacional de Colombia, como en la Ley General de Educación (Ley 115), a la educación se le asigna el papel de función social.

En el examen crítico que Emile Durkheim (1975) realizó al concepto de educación en sus ensayos, la concepción de la educación como proyecto humano trascendente de la Ilustración quedó, al parecer, descartada por la fuerza de la acción práctica del hombre en la sociedad:

Según Kant, el objeto de la educación es desarrollar en cada individuo toda la perfección de que es susceptible. Pero ¿qué debe entenderse por perfección? Es, se ha dicho muchas veces, el desarrollo armónico de todas las facultades humanas. Llevar al punto más elevado que pueda alcanzarse todas las potencias que residen en nosotros, realizadas tan completamente como sea posible, pero sin que se perjudiquen las unas a las otras, ¿no es esto un ideal, al que no puede superar ningún otro? Pero si, hasta cierto punto, este desarrollo armónico es, en efecto, necesario y deseable, no es integralmente realizable; porque está en contradicción con otra regla de la conciencia humana que no es menos imperiosa: la que nos ordena consagramos a una tarea especial y restringida. No podemos y no debemos consagrarnos todos al mismo género de vida; tenemos, según nuestras aptitudes, funciones distintas que desempeñar, y hace falta que nos pongamos a tono con la que nos incumbe. No todos estamos hechos para meditar; hacen falta hombres de sensación y de acción. (p. 43)

En este ensayo publicado en 1922 y que según Maurice Debesse (autor del prólogo) estuvo agotado en las librerías durante mucho tiempo (por lo menos hasta su reedición en 1973), es sorprendente la increíble vigencia de la postura del sociólogo francés sobre la educación, aún para los tiempos actuales, pues todavía se le cita ávidamente. Es probable que, más allá de Durkheim, Educación y sociología (1975) constituya uno de esos textos que funcionan como operadores epistemológicos (Foucault, 2014), posibilitado por la invención de lo social. Esto implica que, dada la vigencia de su concepción sobre la educación del sociólogo, estamos aún algo lejos de superar el discurso social.

Cuando Kant hablaba del progreso no tenía en la cabeza la sociedad, a diferencia de Durkheim. De hecho, lo social era todavía un campo en construcción para su época, harían falta la expansión del utilita- 
rismo y los procesos de nacionalización en Europa y América durante el siglo XIX, para que esta idea alcanzara su nivel de naturalización en las formas de hablar y referirse a la educación. Para Óscar Saldarriaga (2011), lo social

\begin{abstract}
[...] ha de pensarse como construido o "inventado" estratégicamente para producir, conducir, gestionar y determinar las llamadas "necesidades o aspiraciones naturales" y las "reivindicaciones de justicia" de la población en términos de la redistribución de los beneficios económicos a través de "servicios" - estatales o privados-de salud, educación, bienestar seguridad social y servicios públicos. Este campo operaría al menos en dos planos; primero el de la promesa ideal. Es la fe en la satisfacción futura o cubrimiento total de las demandas, que pretende de un lado, dar credibilidad y legitimidad al campo político, y de otro, gestionar los conflictos entre las clases sociales para evitar su desborde. Segundo plano, el de las tecnologías de gobierno: se trata de la implantación de instituciones, sujetos y saberes especializados en lo social para ejercer funciones de extracción de información sobre la vida de "los pobres" o subalternos, configurándolos como objetos de saber, de experimentación y de intervención. (p. 195)
\end{abstract}

A partir del siglo XIX, la sociedad se presenta como un recorte de la humanidad tal y como esta era presentada hasta el siglo XviII. Todo aquello que había sido construido para el logro de esa humanidad cosmopolita fueron dirigidos ahora a la sociedad, y este movimiento debió afectar, de alguna manera, la forma de percibir la educación, que pasó de ser el proyecto humano en sí mismo a constituirse en parte de un servicio, un conjunto de políticas o unas funciones de la misma sociedad. En cierto sentido, el movimiento de la humanidad a la sociedad, despojó a la educación del tiempo y la puso al servicio del presente como medio para alcanzar la promesa ideal como satisfacción de las demandas.

Es el discurso social el que posibilita la edificación de la educación como práctica desplazando el proyecto humano. Este movimiento, al parecer no reconocido, pudo tener efectos considerables sobre la forma en que se percibe la educación, afectando incluso su posibilidad de delimitación y organización en un saber específico como la pedagogía. En estos momentos, la educación es un campo abierto a la opinión, pero paradójicamente, en medio de los cientos de definiciones y percepciones que podemos hallar, hay casi un solo consenso: la educación es concebida de manera generalizada como un hecho social.
El hecho social que instituye la educación como práctica y que la ha dejado sin tiempo y, por tanto, encerrada en el presente, puede estar señalando el ascenso de la sociedad sobre la antropología del humanismo. La sociedad se ha convertido en el ambiente natural de la educación, en algo así como su phusis. Debo reconocer que la idea de asumir la sociedad (y probablemente la cultura) como phusis (o physis) la extraje de la lectura de Paul Veyne (2009), quien en un pequeño apartado del texto Foucault, pensamiento y vida, relata el enfrentamiento del pensador con los historiadores franceses más o menos en los siguientes términos:

Pensando tal vez en el famoso estudio de Heidegger, añadió: "lo único que tienen en la cabeza es la Sociedad, que es lo que la physis era para los griegos". Según decía, los historiadores franceses convertían a la sociedad en el horizonte general del análisis. (p. 32)

¿Estaremos también convirtiendo a la sociedad en el horizonte del análisis de la pedagogía? La phusis, según Pierre Hadot (1998) emerge con la explicación racional del mundo en la Grecia clásica. Y es de manera primordial un esquema cosmogónico y una teoría explicativa racional:

[...] porque pretende explicar el mundo no por medio de una lucha entre elementos, sino de una lucha entre realidades. Esta transformación radical se resume por otra parte en la palabra griega phusis, que, originariamente, significa al mismo tiempo el comienzo, el desarrollo y el resultado del proceso mediante el cual una cosa se constituye. El objeto de su procedimiento intelectual, procedimiento que llaman indagación, historia, es la phusis universal. (p. 22)

Haciendo cuentas, si la sociedad es el principio, desarrollo y fin de la educación, bien podemos establecer que estamos frente a un esquema cosmogónico, una suerte de naturaleza que define todo lo humano, es decir, una phusis contemporánea. La sociedad como entidad plural sería el ambiente en el que tendría lugar todo tipo de desarrollo humano, un hábitat del hombre sin el cual resulta imposible pensarlo. Los proyectos del siglo xx estarían encaminados al diseño de mejores sociedades, ya sea en materia de bienestar o justicia. En la posguerra, el proyecto socialista soviético se vislumbraba como la victoria definitiva de la sociedad, así lo fue por lo menos para la izquierda y la intelectualidad occidental hasta 1989, y esto pudo haber terminado de fortalecer los cimientos de la sociedad sobre los 
vestigios del humanismo. Si había un sueño en el siglo $\mathrm{XX}$, este consistía en caminar hacia un futuro en donde el socialismo se experimentara en distintas formas de intensidad, ya sea anhelando la revolución, la muerte del capitalismo, un modelo de desarrollo para el tercer mundo o la implementación del Estado de bienestar.

El balance elaborado por Robert Dottrens y Gaston Mialaret (1972), titulado "El desarrollo de las ciencias pedagógicas y su estado actual”, y publicado en la importante compilación que realizaron junto con Francine Best y Maurice Debesse sobre Introducción a la pedagogía, por ejemplo, se encuentra enmarcado en esta phusis. En el examen de los autores, las definiciones sobre educación, antes de Durkheim, tenían un carácter individualista:

\section{Kant, menos optimista en cuanto a la excelencia de la naturaleza, asigna a la educación el fin de desa- rrollar "en el individuo toda perfección de que es susceptible". La misma idea aparece en Stuart Mill, ya que para él se trata de acercarnos a la perfección de la naturaleza. Estas definiciones son de carácter individualista. (p. 27)}

La educación, afirman también, había conocido "un punto de vista al que no nos hemos acostumbrado todavía", siendo este el social. Esto se expone como un salto evolutivo en el concepto de la educación, pasando de una concepción individualista a la pluralidad expuesta en la sociedad. Así, la historia del concepto de educación se habría iniciado a partir de Durkheim y la filosofía marxista había terminado de completar:

[...] partiremos de un hecho que domina la evolución de las ideas en materia de educación y pedagogía: la educación está unida a las condiciones de la vida social y política; la pedagogía depende de las concepciones y aspiraciones de aquella. Esta subordinación de la educación al estado social es un hecho social en la historia de la pedagogía de los distintos pueblos. En la medida en que estos han evolucionado cada uno por su propia cuenta de un periodo de civilización a otro, la concepción de la educación y la pedagogía que derivaba se han visto determinados por el o los elementos dominantes en una sociedad dada: autoritarismo del poder eclesiástico y político, acción de las clases dirigentes y concepciones que han tenido de la cultura, etc. Es sorprendente que haya sido preciso llegar hasta Emile Durkheim para que una definición lo reconozca y lo tenga en cuenta. (Dottrens y Mialaret, 1972, p. 30)
El concepto de educación se construyó desde el vínculo social que ofreció Durkheim a comienzos del siglo Xx, y la sociedad se convirtió en el objeto del procedimiento intelectual de la pedagogía. Dotreens y Mialaret creyeron ver apuestas individualistas en el concepto de educación antes de la sociología durkheimniana, exponiendo que el impulso de la sociedad para pensar la pedagogía se habría hecho a partir de la expansión del marxismo. Lo que los autores aún no sabían en la década de 1970, es que la sociedad ya se había tomado, desde antes del florecimiento de la intelectualidad pedagógica marxista, el piso sobre el cual se reedificó el concepto de educación, y que tiene en estos momentos un arraigo tan profundo, que es virtualmente imposible definirla sin la sociedad. Esta última se nos presenta como connatural a la educación, sobre todo cuando se ejecuta la pronunciación del enunciado: la educación es un hecho social.

En el balance que Friedrich W. Kron (2002) realiza sobre los conceptos de la pedagogía, el fenómeno de la socialización y el de la enculturación aparecen como dos grandes esferas sobre las que se fundamenta el concepto contemporáneo de educación. Respecto a la socialización dice:

El medio de la existencia humana es la cultura en la cual vive todo ser humano. Bajo este entendimiento, la sociedad es considerada como un logro cultural específico del hombre para organizarse a sí mismo y a su grupo. La sociedad debe ser considerada como una forma de organización - pero una forma fundamental. Por sí misma es una parte importante de la cultura humana- y como agua para el pez es el medio fundamental para la vida y el aprendizaje humanos. (p. 5)

Cultura y sociedad aparecen como dos esferas amplias, flexibles y de alguna manera con fronteras borrosas entre sí. Para no correr el riesgo de considerar la enculturación y la socialización como dos conceptos iguales o intercambiables, Kron considera la socialización como un proceso parcial de la enculturación:

[...] se refiere a una clase especial de contenidos culturales, es decir sociales. Esencialmente se trata de los valores y de las normas, orientaciones y comportamientos, reglas y roles importantes para una sociedad tal como están representados en las instituciones y enseñados y aprendidos en las diferentes organizaciones. (p. 14)

No obstante, elementos como normas, orientaciones y valores o contenidos culturales vuelven a ser expuestos para intentar definir la educación: 
De esta manera las diferentes interpretaciones del significado de normas y valores culturales, de problemas sociales y de contenido, así como los conflictos pueden ser motivo para la educación. Mediante la reflexión de valores y normas, así como de su interrelación y fundamento, los jóvenes recién aprenden lo que según el filósofo Kant deben aprender primariamente como seres humanos, es decir, "moralidad" expresado moderadamente en juicio y acción moral. (Kron, 2002, p. 23)

El intento de delimitar conceptualmente la socialización de la educación resulta, como se puede observar, poco fructífero. De todas maneras, así se quiera realizar un esfuerzo para exponer la educación como un concepto separado y a la vez relacional a la socialización, priman elementos en común, pese a que a la educación se le estreche para poder aplicarla analíticamente al plano microsocial. Pese a la magnitud de la cultura, es lo social aquello que entreteje todos los conceptos que el autor presenta como propios de la pedagogía.

\section{La naturaleza teleológica de la educación}

Tal vez todavía no estamos seguros si alguna vez existió el hombre racional en los más de doscientos años que nos separan de la Ilustración. Para Kant, este hombre no era ni un tipo de sujeto ni un individuo, era solo aquel que tenía como antítesis el hombre vulgar que "está más propicio a la dirección del mero instinto natural y no consiente a su razón que ejerza gran influencia en su hacer y omitir" (Kant, 2007b, p. 10). El hombre racional, tal como aparece bosquejado en Fundamentación de la metafísica de las costumbres (Kant, 2007b), era más bien un ideal educativo, un proyecto humano general que no es producto de la naturaleza, sino de una acción educativa como acción humana. No obstante, este hombre tampoco se constituye en el fin de la historia, sino que es él quien, en su condición racional, tiene el deber de construir los fines de la historia y realizarlos según sus arreglos.

Es usual encontrar propuestas dirigidas a la superación de la racionalidad moderna. No obstante, también es preciso reconocer que la historia de la educación tiene una profunda deuda con ella, en especial con el proyecto ilustrado. Esta deuda no reside en las reflexiones directas sobre educación que realizaron los pensadores de la modernidad como es el caso de Rousseau, con su Emilio, sino que más bien reside en el hecho de que la modernidad es un proyecto educativo en sí mismo.
En términos estrictos, Kant no habló de educación. El conocido texto Sobre pedagogía (1803) es tal vez el único en el que la referencia de manera explícita, pero habría que tener presente que se trató más bien de unas notas de algunos cursos dictados por el filósofo entre 1776 y 1787, notas que además fueron recogidas por un alumno suyo y publicadas bajo su autorización (Bustamante-Zamudio, 2012). Sin llegar a desmeritar su importancia y utilidad, Sobre pedagogía es tal vez el texto menos pedagógico del filósofo alemán, pues su verdadera apuesta pedagógica está entretejida en toda su obra. En materia de analizar la naturaleza teleológica de la educación, preferimos inclinarnos por sus escritos como Idea de una historia universal en sentido cosmopolita (1784); Si el género humano se halla en progreso constante hacia mejor (1797); El fin de todas las cosas (1794), escritos agrupados todos bajo el título de Teoría de la Historia (1984), de igual manera la revisión de la Crítica de la razón práctica (2003) y Fundamentación de la metafísica de las costumbres (2007) ofrecen un cuadro relativamente completo para analizar las bases filosóficas que hicieron posible la pedagogía.

Los aportes del empirismo inglés, en especial a partir de Locke (1693), habían logrado ofrecer algunos elementos sobre la formación del carácter y el hábito. No obstante, tal vez el distanciamiento con la metafísica impedía la formulación de unos fines generales que sustentaran las razones para efectuar los ejercicios en procura de la formación del hombre. Rousseau completaría este planteamiento desde Emilio o de la educación (1762), en donde la educación tendría como fin la formación de la voluntad general, condición efectiva para la realización del contrato social. A este respecto, Kant va a encontrar una contradicción en la obra de Rousseau que expone en el Comienzo presunto de la historia humana:

\footnotetext{
En su libro sobre la influencia de las ciencias y en el que se ocupa de la desigualdad entre los hombres, nos muestra con gran justeza la contradicción ineludible de la cultura con la naturaleza de la especie humana, en su condición de especie física, en la que cada individuo tendría que alcanzar completamente su destino; pero en el Emilio, en el Contrato socialy en otros escritos trata de resolver de nuevo el grave problema: cómo tiene que proseguir la cultura para que se puedan desarrollar las disposiciones de la humanidad, considerada como especie moral, en forma congruente. (Kant, 1984, p. 79)
}

La primacía de la especie sobre el individuo es clara para el alcance de la humanidad. El análisis que Kant realiza de Rousseau le sirve para ratificar 
el hecho de que fines como la paz perpetua y la libertad solo se logran en el plano de la especie. En otros términos, la historia humana es una historia de perfección, de la guerra a la paz, de la esclavitud a la libertad. Esta perfección a su vez constituye el principio fundamental de la educación que es el proyecto humano en sí. Los fines, como condición inicial, no se logran desde el individuo sino desde la especie, a los hombres singulares -dice en Idea de una historia universal en sentido cosmopolita (Kant, 1984) - el curso se les presenta confuso e irregular. El segundo principio es todavía más incisivo en este aspecto: "en los hombres (como únicas criaturas racionales sobre la tierra) aquellas disposiciones naturales que apuntan al uso de su razón se deben desarrollar completamente en la especie y no en los individuos" (Kant, 1984, p. 42).

La especie, como categoría totalizante que incluye a todos los seres humanos del planeta, tiene una cualidad temporal. Todo lo que toca a ella concierne al tiempo lento, pues el filósofo deja en claro que los fines se alcanzan con lentitud. Este tiempo está expuesto en la relación entre las generaciones, que al parecer, cada una tendría la misión de procurar un mundo mejor a las venideras:

Siempre sorprende que las viejas generaciones parecen afanarse penosamente solo en interés de las venideras, para prepararles un nivel sobre el cual levantar todavía más el edificio cuya construcción les ha asignado la Naturaleza; y que solo las generaciones últimas gozarán la dicha de habitar en la mansión que toda una serie de antepasados, que no la disfrutará, ha preparado sin pensar en ello. (Kant, 1984, p. 45)

Cuando anota que "parece que a la Naturaleza no le interesaba que el hombre viviera bien; sino que se desenvolviera a tal grado que, por su comportamiento, fuera digno de la vida y del bienestar" (p. 45), expone los fines como una conquista exclusivamente humana, e incluso contraria a la naturaleza. El uso de la razón, como única facultad dada, y el trabajo en procura de un mejor mundo por las generaciones venideras, serían las claves para la conquista de la inmortalidad. Los seres humanos son entonces mortales como individuos, pero inmortales como especie. Esta inmortalidad, no obstante, es ganada mediante "la perfección del desarrollo de sus disposiciones" (p. 46).

El mundo mejor, metaforizado en la mansión que se perfecciona de generación en generación, presenta el trabajo temporal de la educación como una arquitectura. La perfección no se alcanza sin trabajo, y este trabajo es necesariamente un trabajo de educación. En el cuarto principio, relacionado con la insociable sociabilidad, expone el lento desarrollo de los talentos, que le permiten al hombre pasar de la disposición natural (insociabilidad) a la disposición moral (sociabilidad).

La inmortalidad, la libertad y la paz perpetua formarían parte de las reflexiones de orden metafísico según Kant. La educación, como gran proyecto de perfección humana, posibilita que la pedagogía, no sea necesariamente una ciencia que se ocupe de forma exclusiva de asuntos prácticos y empíricos, excluyendo de plano su relación con estas cuestiones metafísicas. No se trata, tampoco, de una pedagogía que se preocupe solo de asuntos metafísicos, pero si todavía creemos en la posibilidad de formular fines de la educación, y estos fines tienen que ver con la idea de perfección humana, entonces no debemos rechazar de plano el principio de inmanencia que propone Kant, en el que se excluyen los intereses económicos o ideológicos en el alcance de tales fines. Una pedagogía así no reside exclusivamente en el orden de la práctica o de la socialización del hombre, se trataría más bien de una pedagogía inmanente.

Pensada así la pedagogía, la educación no solo debería asumirse como un conjunto de asuntos prácticos y fenoménicos, sino que también debería examinar su cualidad apriorística. En Si el género humano se halla en progreso constante hacia mejor (Kant, 1984) se pregunta ¿cómo es posible una historia a priori?, seguido se responde: "si el profeta él mismo hace y dispone los hechos que anuncia con anticipación" (p. 96). El tiempo de la historia es el tiempo del progreso en tanto la única condición de conocerla y narrarla es la perfección humana, y en este sentido, los fines de la educación serían los mismos de la historia. De esto podríamos deducir que la educación está presente cuando hay un plan o unos fines de perfección que trascienden el presente y las condiciones naturales como el individuo y sus necesidades. Si la educación carece de esta cualidad temporal, y si los fines ya no se formulan para la especie sino para las contingencias del presente o una generación en particular, la educación pierde su condición a priori y, por tanto, el tiempo se detiene, o en el peor de los casos, se trataría de un tiempo antinatural como retroceso, aquel "provocado por nosotros mismos al comprender equivocadamente el fin último" (Kant, 1984, p. 132).

¿Cuáles son, pues, esos fines de la educación expuestos como fines de la historia? Aunque Kant los agrupa en fines subjetivos y fines objetivos, estos ya habían transitado por la historia de Europa desde el siglo IV a.C. Aristóteles (2005) ya los había 
mencionado, pero en la versión kantiana los fines se resumen en un solo fin universal: se trata del hombre como fin en sí mismo, y para alcanzarlo, sería necesaria la formación de una voluntad buena (Kant, 2007). A la manera aristotélica, es preciso alcanzar la voluntad buena porque "el hombre es el inicio de las acciones", y solo así se lograría: "que rectifique y acomode a un fin universal el influjo de esa felicidad y con él el principio todo de la acción" (Kant, 2007b, p. 7).

¿En qué orden, únicamente, se puede esperar el progreso hacia mejor?, se pregunta Kant en Ideas para una historia universal en sentido cosmopolita, y se responde seguido:

\begin{abstract}
[...] no por el curso de las cosas de abajo arriba, sino de arriba abajo. Esperar que mediante la educación de la juventud, con la instrucción doméstica y más tarde escolar, de la escuela elemental a la superior, en una cultura espiritual y moral fortalecida por la enseñanza religiosa, se llegase a formar no solo buenos ciudadanos, sino dados al bien, capaces de sostenerse y progresar siempre, he aquí un plan cuyo logro parece difícil. (Kant, 1984, p. 115)
\end{abstract}

\section{La crisis de la educación como crisis del tiempo. Algunas notas para concluir}

“¡Pobres mortales, nada hay entre vosotros constante más que la inconstancia!". Esta es la exclamación que Kant usa en El fin de todas las cosas para referirse a aquellos proyectos que cambian "de tiempo en tiempo y a menudo se contradicen” (Kant, 1984, p. 137). En los tiempos contemporáneos, todo se nos presenta bajo las sensaciones de velocidad y aceleración. Las políticas sobre educación en Colombia, por ejemplo, manifiestan un afán renovador por reorganizar el sistema educativo. El Estado viene realizando desde 1995 los llamados Planes Decenales de Educación, en donde se proyecta a diez años lo que se espera de la educación nacional. El último plan vigente se refiere a la educación en los siguientes términos:

Los gobiernos del mundo han puesto sus ojos en la educación como una poderosa herramienta de transformación, que facilita el fortalecimiento de la democracia, genera movilidad social y reduce las desigualdades sociales y económicas. La Organización de las Naciones Unidas pudo establecer, utilizando datos correspondientes a 114 países, entre 1985 y 2005, que un año más de educación está asociado directamente a una reducción de

3 Puede identificarse este argumento en Aristóteles (2005).
1,4 puntos porcentuales del coeficiente de Gini, principal indicador que mide la desigualdad. (MEN, 2017, p. 9)

Si nos fijamos bien, este fragmento del Plan Decenal de Educación 2016-2026 expone la democracia, la movilidad social y la reducción de las desigualdades económicas como fines alcanzables a diez años, siendo la educación el medio o la herramienta para su consecución. La Ley General de Educación (Ley 115 de 1994) propone trece fines, que si se revisan con cuidado, están formulados desde la individualidad como el desarrollo de la personalidad, la participación política, la formación práctica para el trabajo, entre otros. En un sentido estricto, por lo menos desde que el sistema educativo ha alcanzado su máximo tope de cobertura, los fines no se proyectan para la educación, más bien parecen actividades y metas de alcance para el sistema educativo.

Por lo menos desde la legislación colombiana se podría decir que no hay fines educativos, en la medida en que el alcance de la participación política, la ciudadanía, la convivencia pacífica o la formación para el trabajo son medios para alcanzar los niveles de desarrollo, expuestos en el plano económico y social. La meta está puesta en solucionar unos problemas contingentes del presente, como el aumento de la productividad y el de los ingresos. La ausencia de unos fines que estén relacionados con la perfección humana, sin mediar en ellos el interés económico o ideológico, manifiesta cierto malestar que puede interpretarse como una crisis la educación como crisis del tiempo.

Lo que se la ha reclamado a Kant, desde Emile Durkheim (1975) a Max Horkheimer y Theodor W. Adorno (1998) es la imposibilidad de llevar a la realidad el proyecto humano. Sin embargo, Kant nunca propuso que este proyecto humano debía acelerarse o aplicarse en un tiempo corto y limitado. El tiempo del progreso kantiano es un tiempo lento, capaz de llevar a la especie a la inmortalidad. Las reclamaciones que se le hacen en el siglo xx están hechas desde un tiempo en aceleración. Desde la Revolución rusa en 1917, este siglo se ha caracterizado por acelerar los procesos que la modernidad clásica había expuesto en un futuro abierto. Al parecer este afán radique en que el futuro está experimentándose de nuevo en la finitud que lo había caracterizado hasta el siglo XVI. Si esto es así, el tiempo se ha detenido y el progreso, en su versión filosófica, se ha agotado de manera definitiva. La paradoja es que a mayor aceleración más se experimenta la detención del tiempo, pues el futuro, como consecución de la justicia y la igualdad, puede alcanzarse a solo diez años. 
Esta crisis del tiempo parece equipararse al fin de la historia que haría evidente Francis Fukuyama (1989) tras la caída del Muro de Berlín. La historia que llegó a su fin, a juicio de Fukuyama, es precisamente la historia que partía desde la línea KantHegel-Marx: "la historia como proceso único, evolutivo, coherente" (p. 12), el fin, "significaba que no había nuevos progresos en el desarrollo de los principios e instituciones subyacentes, porque todos los problemas realmente cruciales habían sido resueltos" (p. 13). El final del siglo xx experimentó el triunfo pleno del liberalismo, y las consecuencias devastadoras de la posguerra "parece negar que exista algo que pueda llamarse progreso histórico" (p. 13).

Por su parte Marc Augé (2012) establecería que, si en efecto hay una crisis de la historia, esta obedece a la renuncia de la educación como utopía de la educación producida por una honda desconfianza en el futuro:

La utopía de la educación es en lo sucesivo la única esperanza de reorientar la historia de los hombres en la dirección de los fines. ¿Por qué utopía? De hecho, el término utopía, en este uso, solo tiene sentido en la relación con las políticas actuales que van todas en el mal sentido, independientemente de lo que pretendan, porque estas al mismo tiempo se resignan al fracaso escolar, vinculan estrechamente la cuestión de la escuela o de la universidad con la del empleo, no se ocupan lo suficiente de crear las condiciones de una cultura general que no dependa del entorno familiar o social y, en resumen, descuidan la cuestión de los fines o la limitan al ámbito de la economía afirmando, por ejemplo, que el regreso al crecimiento es una condición previa absoluta a toda iniciativa social. (p. 128)

Para finalizar, consideramos que esta crisis también trae consigo otros elementos que deben analizarse a la luz de las exposiciones sobre el detrimento de los fines. Tenemos fuertes sospechas de que el encierro sobre la práctica como experiencialismo, proveniente de la tendencia sociologicista de la educación, pueda estar relacionado con la aceleración y detención de la educación como tiempo futuro. La apertura a lo social, como Daniel Tröhler (2014) también lo llama educacionalización, pudo haber impulsado a su vez la apertura de la opinión y la intervención sobre la educación, lo que produjo una cacofonía de opiniones y críticas que, de alguna manera, impidieron que educación se organizara como un concepto técnico de la pedagogía. En su contrario, la educación se ha establecido como un campo abierto a la opinión, incluso desde los frentes menos autorizados, un campo problemático y de dominio público, un debate que ya en Colombia tiene más de cien años.

\section{Referencias}

Aristóteles (2005). Ética a Nicómaco. Versión revisada. Madrid: Alianza.

Augé, M. (2012). Futuro. Buenos Aires: Adriana Arango.

Bloch, M. (1982). Introducción a la historia. México: Fondo de Cultura Económica.

Bustamante-Zamudio, G. (2012). Pedagogía de Kant: ¿una filosofía de la educación? Magis, Revista Internacional de Investigación en Educación, 5(10), 155-171.

Congreso de la República de Colombia. Ley 115 de febrero 8 de 1994. Por la cual se expide la Ley General de Educación. Bogotá.

Dottrens R. y Mialaret, G. (1972). El desarrollo de las ciencias pedagógicas y su estado actual. En F. Best y M. Debesse (eds.), Introducción a la pedagogía (pp. 25-35). Barcelona: Oikos.

Durkheim, E. (1975). Educación y sociología. Barcelona: Península.

Foucault, M. (1990). Tecnologías del yo y otros textos afines. Barcelona: Paidós.

Foucault, M. (2005). El orden del discurso. Buenos Aires: Tusquets.

Foucault, M. (2014). Lecciones sobre la voluntad de saber. Curso en el College de France (1970-1971). México: Fondo de Cultura Económica.

Fukuyama, F. (1993). El fin de la historia y el último hombre. Bogotá: Planeta.

Hadot, P. (1998). ¿Qué es la filosofía antigua? México: Fondo de Cultura Económica.

Horkheimer, M. y Adorno, T. (1998). Dialéctica de la Ilustración. Fragmentos filosóficos. Valladolid: Trotta.

Kant, I. (1984). Filosofía de la historia. Madrid: Fondo de Cultura Económica.

Kant, I. (2003). Crítica de la razón práctica. Buenos Aires: Losada.

Kant, I. (2007a). Crítica de la razón pura. Buenos Aires: Losada.

Kant, I. (2007b). Fundamentación de la metafísica de las costumbres. Madrid: Alianza. 
Koselleck, R. (1993) Futuro pasado. Para una semántica de los tiempos históricos. Barcelona: Paidós.

Kron, F. (2002). Términos básicos de la pedagogía. En W. Küper (ed.), Pedagogía General (pp. 5-59). Quito: Abya-Yala.

Le Goff, P. (1991). El orden de la memoria. El tiempo como imaginario. Barcelona: Paidós.

Ministerio de Educación Nacional (MEN). (2017). Plan Nacional Decenal de Educación 2016-2026. El camino hacia la calidad y la equidad. Bogotá.
Noguera, C. (2012). El gobierno pedagógico. Del arte de educar a las tradiciones pedagógicas. Bogotá: Siglo del Hombre.

Saldarriaga, Ó. (2011). El oficio del maestro. Prácticas y teorías de la pedagogía en Colombia. Bogotá: Magisterio.

Tröhler, D. (2014). Pestalozzi y la educacionalización del mundo. Barcelona: Octaedro.

Veyne, P. (2009). Foucault, pensamiento y vida. Barcelona: Paidós. 